\title{
Total diz protezi sonrası komplikasyonlar
}

\author{
Complications after total knee arthroplasty
}

\author{
Alican Barış, Yusuf Öztürkmen
}

SBÜ, İstanbul Eğitim ve Araştırma Hastanesi, Ortopedi ve Travmatoloji Kliniği, İstanbul

Total diz protezi (TDP), gonartroz hastalarında fonksiyonel sonuç ve ağrının giderilmesi açısından tatmin edici bir cerrahi prosedürdür. Artan TDP sayıları ve genişleyen endikasyonlar ile birlikte komplikasyon da giderek artmaktadır. Total diz protezine bağlı komplikasyonlar; hastanın cerrahi yapılacak dizinin artroz seviyesine ve hastanın genel sağlık durumuna, cerrahın beceri ve tecrübesine, kullanılan implantın özelliklerine, cerrahi yönteme, ameliyat sonrası bakım ve takibe göre çeşitlilik göstermektedir. Bu komplikasyonların bir çoğu konservatifyöntemler ile tolere edilebilirken bazı durumlarda ise revizyon cerrahisi gerektirebilmektedir. Enfeksiyon ve instabilite erken dönemde, polietilen aşınması ve aseptik gevşeme ise geç dönemde en sık revizyon gerektiren komplikasyonlardır. Uygun hasta seçimi, hastanın ameliyat öncesi eşlik eden hastalıklarının (komorbidite) durumunun iyileştirilmesi, özenli sterilizasyon, uygun cerrahi girişim, yeterli yumuşak doku dengesinin sağlanması, doğru implant dizilimi, eklem hattının restorasyonu ve ameliyat sonrası yakın takip ile TDP'ye bağlı komplikasyonlar minimalize edilebilmektedir.

Anahtar sözcükler: diz; gonartroz; protez; komplikasyon
Total knee arthroplasty (TKA) is a very successful procedure in alleviating pain and improving function in patients with gonarthrosis. The rate of complications are rising due to the higher number of operations and indications. Complications after primary TKA differ regarding the level of arthrosis in the operated knee, general health status of the patient, experience and talent of the operating surgeon, characteristics of the implant, surgical method, postoperative care and follow-up. Most of these complications are tolerated with conservative management but in some cases revision surgery is needed. Infection and instability are the two main complications requiring early revision surgery. However polyethylene wear and aseptic loosening are the two complications mostly requiring a revision surgery in the late postoperative period. Complications of TKA can be minimized with a proper patient selection, improvement of preoperative comorbidities, careful sterilization, appropriate surgical approach, adequate soft-tissue balance, correct implant alignment, restoration of joint line and close follow-up of patients.

Key words: knee; gonarthrosis; prosthesis; complication
T otal diz protezi (TDP); ileri diz osteoartrit olgularında en sık uygulanan cerrahi işlemdir. Ağrıyı azaltmasının yanı sıra fonksiyonel iyileşmeye de katkı sağlar.[1] Total diz protezi sayısında son zamanlarda büyük ölçüde artış sağlanmıştır. Gelecek on yıllarda bu artışın giderek katlanacağı ön görülmektedir. ${ }^{[2]} \mathrm{Bu}$ işlemin artışı ile birlikte komplikasyonları da önem kazanmaya başlamıştır. Total diz protezinde komplikasyonlar; hasta seçimi, kullanılan implant, cerrahi yöntem, ameliyat sonrası bakım ve takip ile ilgili olabilmektedir. Diz Derneği (The Knee Society) tarafından TDP sonrası olası komplikasyonlar; kanama, yara sorunları, tromboemboli, damar-sinir hasarı, medial kollateral bağ yaralanması, instabilite, dizilim bozukluğu, eklem sertliği, derin periprostetik eklem enfeksiyonu, osteoliz, periprostetik kırık, ekstansör mekanizma bozukluğu, patellofemoral çıkık, tibiofemoral çıkık, implant yüzey aşınması, implant gevşemesi, implant kırığı, tibial insert ayrışması, tekrarlayan hastane başvurusu, tekrarlayan ameliyat, revizyon, ölüm vb. şeklinde belirtilmiştir. ${ }^{[3]}$

\section{KANAMA VE VASKÜLER YARALANMA}

Total diz protezi sonrası basit kanamalar olabileceği gibi uzuv kaybına neden olan veya yaşamı tehdit eden ciddi yaralanmalar da olabilmektedir. Majör vasküler yaralanma insidansı \%0,05 olarak bildirilmiştir. Genikulat arter, popliteal arter, yüzeyel femoral arter ve anterior tibial arter en sık bildirilen majör damar yaralanmalarıdır (Şekil 1). ${ }^{[4,5]}$

İletişim / Contact: Prof. Dr. Yusuf Öztürkmen • E-posta / E-mail: yozturkmen@gmail.com

ORCID iD: Alican Barış, 0000-0001-6031-6777 • Yusuf Öztürkmen, 0000-0002-2199-2411

Geliş / Received: 12 Temmuz 2021 • Kabul / Accepted: 24 Temmuz 2021 


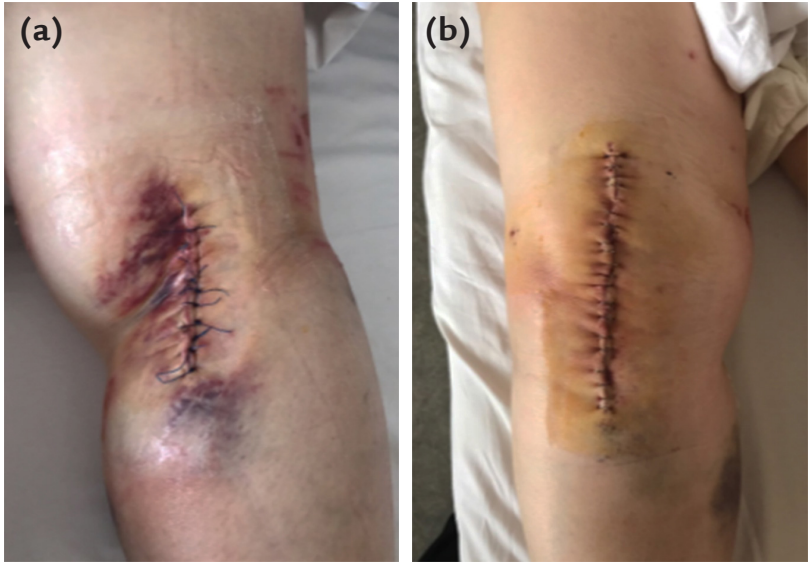

Şekil 1. a, b. TDP sonrası major damar tamiri; damar tamirinin yapıldığı popliteal bölgeden (a) ve önden (b) görünüm.

Total diz protezi sonrası damar yaralanmalarının \%36'sı ameliyat sonrası birinci günde tanı alabilmektedir. Majör vasküler yaralanma olan hastaların yaklaşık $1 / 5$ 'inde amputasyon veya uzun süreli nörolojik komplikasyonlar olmaktadır. Femoral arter oklüzyonu, popliteal arter transeksiyonu (enine kesisi) ve popliteal arter arteriovenöz fistülü en sık amputasyona neden olan damar yaralanmalardır ${ }^{[4,5]}$.

Bilinen periferik vasküler hastalık, diyabet, hipertansiyon veya sigara alışkanlığı gibi vasküler yaralanma riski olan hastalarda TDP öncesi damar cerrahisi görüşü önerilmektedir. Cerrahi esnasında ekibin ihtiyatlı davranması, manipülasyonların nazik bir şekilde yapılması, cerrahi aletlerin düzgün yerleştirilmesi olası vasküler yaralanmaları azaltacağı bildirilmektedir. ${ }^{[4]}$

\section{TEKRARLAYAN HEMARTROZLAR}

Tekrarlayan hemartrozların insidansı \%0,1 ile \%1,6 arasında olduğu tahmin edilmektedir. Düşük insidansa sahip olmasına rağmen hasta ve cerrah için moral bozukluğuna neden olabilmektedir (Şekil 2). ${ }^{6]}$

Genel olarak sistemik faktörler (antikoagülan kullanımı, kanama bozuklukları), lokal diz faktörleri (pigmentli villonodüler sinovit, kristalize-inflamatuvar artropatiler, metallere karşı aşırı duyarlılık, arteriovenöz malformasyonlar, doku travması, implant gevşemeleri) ve iyatojenik faktörler (tespit edilememiş damar yaralanmaları, implant yerleşim bozuklukları) şeklinde olası etiyolojik nedenleri belirtilmiştir. $^{[7]}$ Konservatif tedavi geçici bir rahatlama sağlasa da nüks oranı yüksektir. İnatçı olgularda artroskopik veya açık sinovektomi, anjiyografik embolizasyon veya revizyon cerrahisi yapılabilmektedir. ${ }^{[6]}$

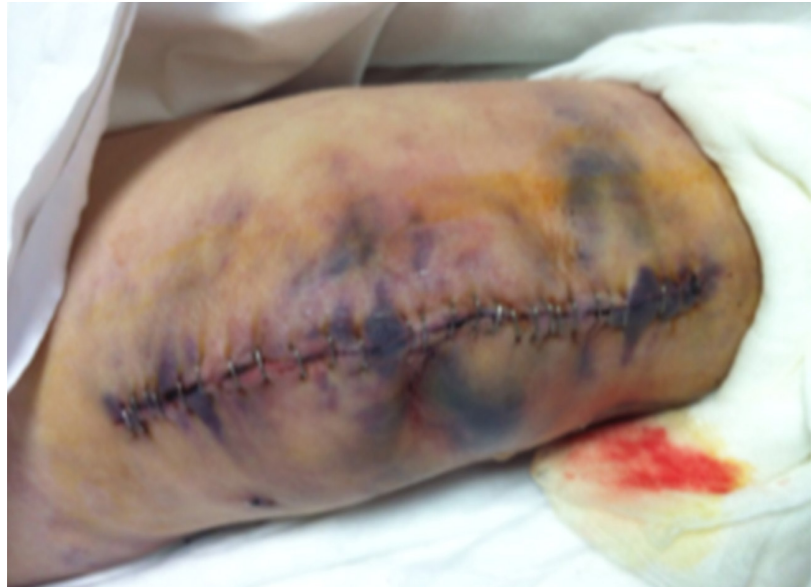

Şekil 2. TDP sonrası tekrarlayan hemartroz.

\section{AMELIYAT YARASI PROBLEMLERI}

Cerrahi gerektiren yara problemleri \%0,33 oranında bildirilmektedir. Diyabet, anemi, romatoid artrit, obezite, beslenme bozukluğu ve sigara alışkanlığı yara komplikasyon riskini artırmaktadır. Diz çevresinin cildini besleyen perforan damarlar çoğunlukla diz medialinden kaynaklanmaktadır. Mediale yakın insizyonlar bu kan akımını sekteye uğratarak yara iyileşme problemlerine yol açabilmektedir. Ayrıca ameliyat esnasında genikulat arterlerin yaralanması sonucu flep gerektiren yara komplikasyonlarına neden olabilmektedir (Şekil 3). ${ }^{[8]}$

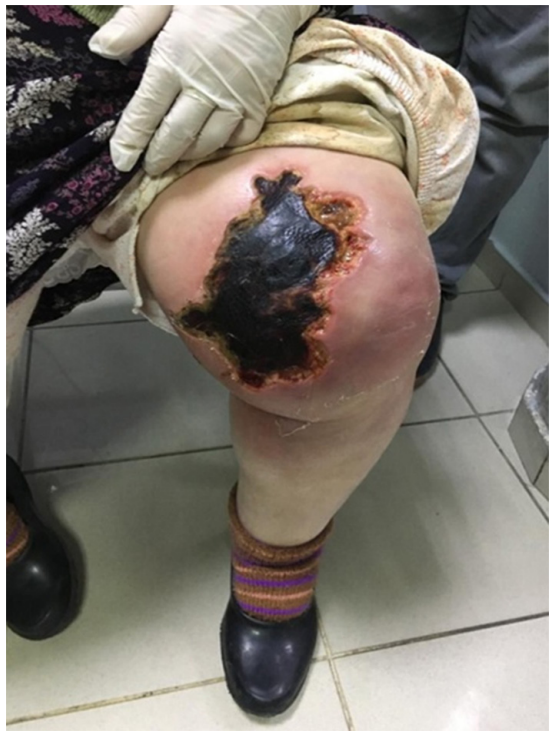

Şekil 3. TDP sonrası yara iyileşme sorunu ve yumuşak doku nekrozu. 

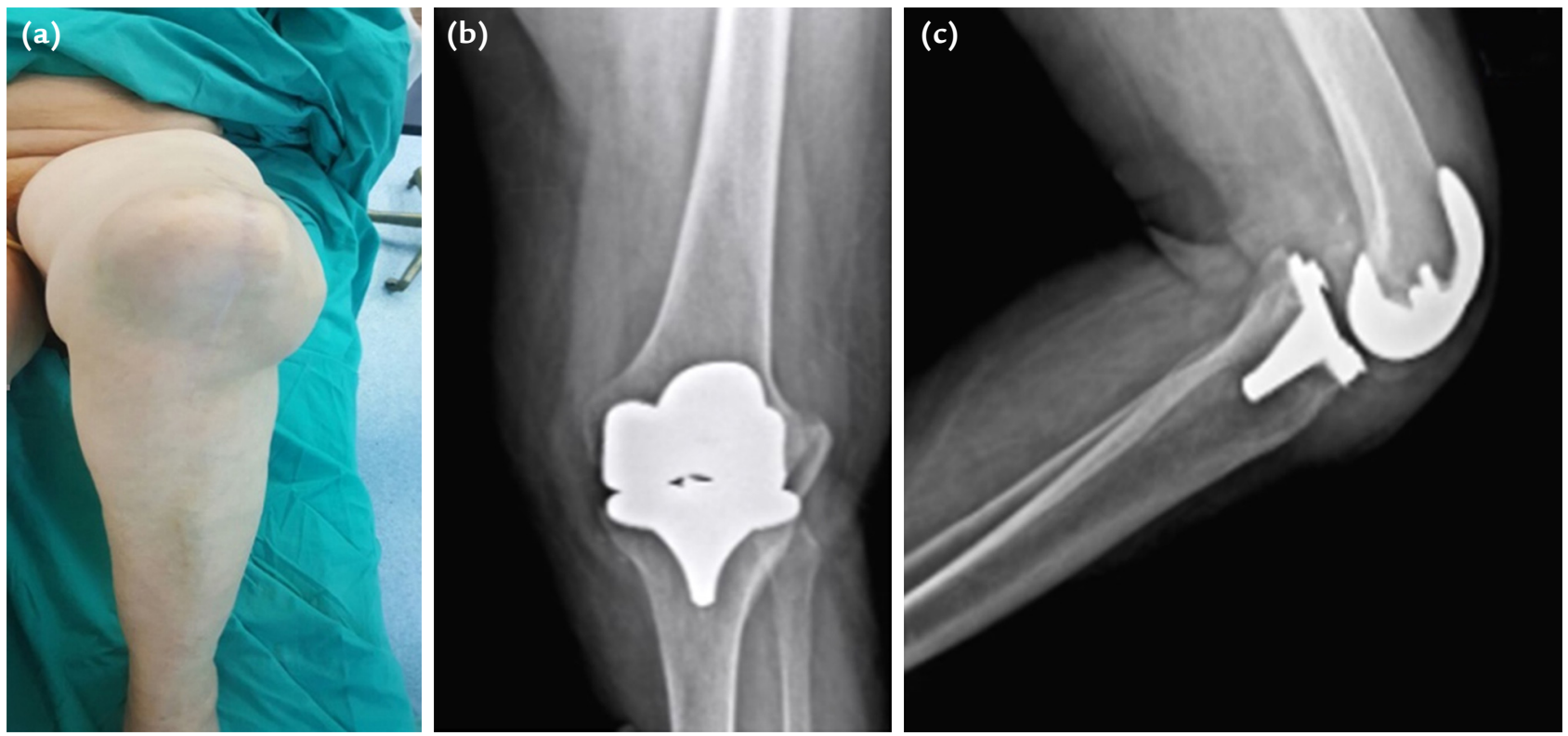

Şekil 4. a-c. TDP sonrası patella çıkığı; klinik görünüm (a) ile ön-arka (b) ve yan (c) grafiler.

Düzgün yara iyileşmesini sağlamak için değiştirilebilir risk faktörleri ameliyat öncesinden ele alınmalıdır. Ameliyat esnasında yumuşak doku hasarının en aza indirecek şekilde titiz cerrahi işlem uygulanmalıdır. Ameliyat sonrası yeterli drenaj sağlanıp yara bakım ve takibi düzgün yapılmalıdır. ${ }^{[8,9]}$

\section{PATELLAR KOMPLIKASYONLAR}

Patellar komplikasyonlar oldukça yaygındır. İmplant tasarımı ve cerrahi teknikteki gelişmelere rağmen TDP sonrası komplikasyonlarının yaklaşık \%10'unu oluşturmaktadır. ${ }^{[2,10]}$ Bu komplikasyonların altında yatan mekanizmalar iyi tanımlanmadığı takdirde hedef sonuca ulaşmayan tekrarlayıcı ameliyatlara sebep olabilmektedir. ${ }^{[11]}$

\section{Patellar Komplikasyon Risk Faktörleri}

Hasta ile ilişkili risk faktörleri: Obezite, $10^{\circ}$ ve üzeri valgus, patellar kalınlığın 18 mm altında olması, patellar tilt veya subluksasyon. ${ }^{[12]}$

Cerrahi ile ilişkili risk faktörleri: Patellar kesinin abartılı yapılması (12 mm ve üzeri patellar kalınlık korunmalı) ${ }^{[12]}$, asimetrik kemik kesisi ( $2 \mathrm{~mm}$ üzeri asimetrik kesiler risk oluşturur $)^{[13]}$, patellar kanlanmanın bozulması, femoral ve/veya tibial komponentlerin yerleşim bozukluğu, patello-femoral offset değişimi..[14,15]

Protez ile ilişkili risk faktörleri: Femoral komponent oluğunun genişliği, komponentin kalınlığı, patellar implantın özellikleri, troklear uyum. ${ }^{[2]}$

\section{Patella Kırıkları}

Total diz protezi sonrası patella kırıkları \%1,9 oranında görülmektedir. Travma veya patella osteonekrozundan kaynaklanabilmektedir. Patella kırıklarının yaklaşık \%10'unun belirgin travma öyküsü varken çoğunluğu kontrol muayenelerinde tespit edilmektedir. Bu kırıkların büyük bir bölümü TDP sonrası iki yıl içerisinde gerçekleşmektedir. Tedavide ekstansör mekanizma ve patellar implantın durumu belirleyici olmaktadır. Ekstansör mekanizma bozulmuşsa veya patellar implant gevşemiş̧ ise bu kırıklara cerrahi tedavi önerilmektedir. Her ikisinin de sağlam olduğu çoğu durumda konservatif kalınmaktadır. ${ }^{[2,16]}$

\section{Patella Subluksasyonu ve Patella Çıkığı}

Total diz protezi sonrası patella çıkıklığı \%2 oranında bildirilmektedir. Çoğu olgu ameliyattaki teknik hatalardan kaynaklanmaktadır. Komponent malrotasyonu, uygunsuz patellar hazırlık (malpozisyon veya asimetrik kemik rezeksiyonu), yumuşak doku dengesizliği (medial retinaküler yetmezlik, vastus medialis kasının zayıflı̆̆, kuadriseps kas kontraktürü, iliotibial bant gerginliği), valgus dizilim bozukluğu ( $Q$ açısını etkileyerek ekstansör mekanizma üzerinde dengesiz çekme yapar), protez tasarımındaki eksiklikler veya travma gibi problemler patella çıkığına neden olabilmektedirler (Şekil 4). ${ }^{[17]}$

Femoral komponentin iç rotasyonda yerleştirilmesi troklear oluğu mediale yer değiştirtir. Bu lateral retinakulumun gerilimini artırarak patellanın laterale çıkma 
eğilimini artırır. Tibial komponentin aşırı iç rotasyonda yerleştirildiğinde ise diz fleksiyonu sırasında tibia dış rotasyonu zorlanır. Tüberkül ile beraber patellanın laterale kayma eğilimi artar. Sonuç olarak her iki komponentin aşırı iç rotasyonda yerleştirilmesi patellar çıkık riskini artırmaktadır. ${ }^{[17,18]}$ Patellar çıkığı olan hastalarda, ambulasyon yeteneğini yeniden kazanmak için genellikle revizyon cerrahisi gereklidir. Komponentlerin malpoziyonu durumlarında tüberositas tibia osteotomisi, lateral retinakuler gevşetme, medial patellofemoral ligament augmentasyonu veya rekonstrüksiyonu gibi cerrahi tedaviler önerilmektedir. Bazı olgularda protez değişimi gerektirebilmektedir. ${ }^{[2,19]}$

\section{Patellar Clunk Sendromu ve Krepitus}

Clunk sendromu ve krepitus hastaların \%0-\%18'inde görülebilmektedir. Tanı klinik muayene ile konulur. Clunk sendromu için bazı risk faktörleri tanımlanmıştır. Femoral komponentin aşırı geniş ve keskin kenarlı interkondiler bölgeye sahip olması ana risk faktörü olarak tanımlanmışsa da; küçük femoral veya tibial komponent, ince patella, artmış posterior offset ve zorlu diz fleksiyonu gibi risk faktörlerinin de olabileceği bildirilmektedir. ${ }^{[2,20,21]}$ Clunk aktif diz ekstansiyonu esnasında diz yaklaşık $30^{\circ}-45^{\circ}$ fleksiyonda iken meydana gelir. Dizde ses ile birlikte bir tutukluluk meydana gelir. Patella proksimalinde oluşan bir skar nodülünün clunk sendromuna neden olduğu bildirilmektedir. Nodül, posterior stabilize femoral komponentin interkondiler bölgesine tutukluluğa neden olmaktadır. Krepitus ise eklem içi fibröz bantlar nedeniyle oluşmaktadır. Clunk sendromunda fizyoterapi öncelikli tedavi yöntemidir. Fizyoterapi ile yeterli sonuç alınamayan olgularda artroskopik rezeksiyon önerilir. İnatçı ve tekrarlayan olgularda nodül eksizyonu için açık cerrahi yöntemine başvurulmaktadır. ${ }^{[2]}$

\section{Diz Önü Ağrısı}

Total diz protezi olan olguların yaklaşık $1 / 5^{\prime}$ inde görülebilmektedir. Diz önü ağrısı yapan durumların çoğu patellar komplikasyonlar ile ilişkili bir mekanizmadan kaynaklandığı düşünülmektedir. Bunlar; patellanın avasküler nekrozu, patellofemoral impingement, patellar implant gevşemeleri, asimetrik patellar kesi, patellar clunk sendromu, rotasyonel yerleşim bozuklukları vb.'dir. Total diz protezi sonrası diz önü ağrısı olan olguların \%10-\%15'inde ağıının kaynağını açıklayabilecek bir mekanizma gösterilememiştir. ${ }^{[22]}$ Patellar yüzey yenilemesi yapılmaması da diz önü ağrısına neden olabilmektedir. Bu durumda ağrıyı önlemek için patellar denervasyon önerilmiştir. Fakat bu yöntemin sağladığı yararın zamanla azaldığı görülmüştür. Patelloplastinin (osteofit rezeksiyonu) diz önü ağrısını önlemede basit denervasyondan daha etkin olduğu bildirilmiştir. ${ }^{[2]}$

\section{EKSTANSÖR MEKANIZMA PROBLEMLERI}

Kuadriseps tendonu, patella ve patellar tendon ekstansör mekanizmayı oluşturmaktadırlar. Patellofemoral eklem üzerindeki kuvvetlerin incelenmesi neticesinde yürüme esnasında vücut ağılığının yaklaşık yarısının ekstansör mekanizma ile iletildiği tespit edilmiştir. Merdiven çıkma ve çömelme esnasında patellofemoral ekleme yansıyan kurvetin sırasıyla 3,1 ve 7 katına çıktı̆̆ı görülmüşsür. ${ }^{[23]} \mathrm{Bu}$ mekanizmayı oluşturan tendonların rüptürleri patella kırıklarına göre daha az sıklıkta görülmekte fakat en az patella kırıkları kadar yıkıcı sonuçlara neden olabilmektedir. ${ }^{[24]}$ Ekstansör mekanizma problemleri TDP cerrahisi esnasında veya sonrasında görülebilen uğraştırıcı ve sıkıntılı komplikasyonlardır. Total diz protezi uygulanan hastaların yaklaşık \%1-\%12'sinde ekstansör mekanizma problemleri görülebilmektedir. Kuadriseps tendon rüptürü $\% 0,1$ oranında iken patellar tendon rüptürü $\% 0,17$ oranında olduğu bildirilmektedir. ${ }^{[23]}$ Geleneksel olarak bu yaralanmaların tedavisinde tendonun doğrudan onarımı tercih edilmekte idi. Bu yöntemin yüksek başarısızlık oranları nedeniyle son zamanlarda rekonstrüksiyonun daha çok tercih edilen tedavi yöntemi haline geldiği bildirilmektedir. ${ }^{[24]}$ Patellar tendon rüptürünün rekonstrüksiyonunun onarımdan çok daha düşük komplikasyon oranına sahip olduğu görülmüştür. Bundan dolayı akut veya kronik patellar tendon rüptürünün birinci tedavi seçeneği için rekonstrüksiyon önerilmektedir (Şekil 5). [23]

Kuadriseps tendon rüptürünün akut döneminde primer onarım yapılabilmektedir. Revizyon cerrahisi esnasından veya kronik dönemde ise greft ile kuadriseps tendon rekonstrüksiyonunun endike olduğu bildirilmektedir. ${ }^{[23]}$

\section{Tibiofemoral Çıkık}

Tibiofemoral çıkık, tibial komponentin femoral komponent ile olan ilişkisinin bozulması olarak tanımlanır. Çoğunlukla tibial komponent sagittal planda femoral komponente göre posteriora kayar (Şekil 6). ${ }^{[25]}$ Literatürde nadiren bildirilen bir komplikasyondur. Primer TDP'de sıklığın \%0,15 ile \%0,5 arasında, revizyon cerrahisinde ise \%3,3 civarında olduğu tahmin edilmektedir.[26] Total diz protezi sonrası diz çıkığı normal diz çıkığı kadar ciddi olmasına ve hatta amputasyona yol açabilmesine rağmen verilerin azlığı nedeniyle etiyolojik nedenleri daha tam olarak aydınlatılamamıştır. ${ }^{[26,27]}$ Obezite, kadın cinsiyet ve komorbidite durumlarında daha fazla olduğu görülmüştür. Komponent malpozisyonu, fleksion-ekstansiyon sırasındaki eklem aralığı uyumsuzluğu, bağ koruyan protez tasarımlarında arka çapraz bağ rüptürleri, 

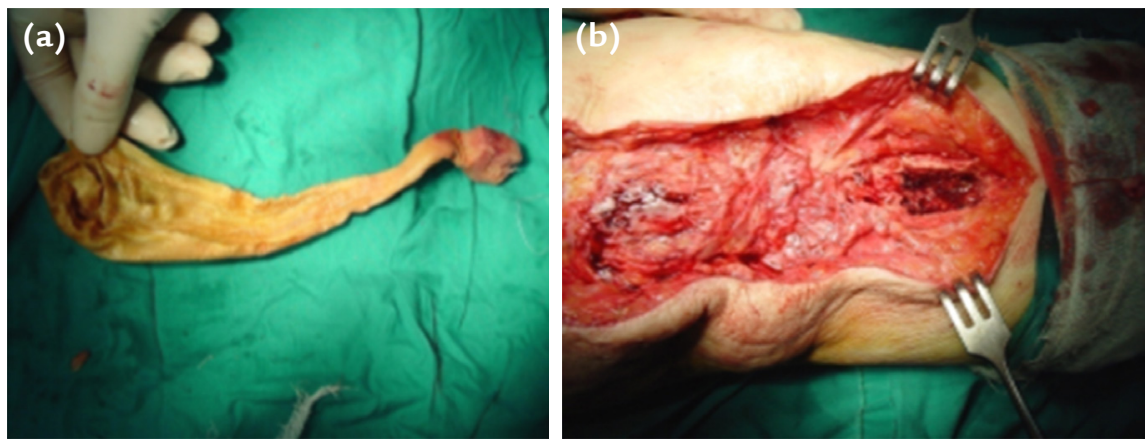

Şekil 5. a-d. Allogreft ile patellar tendon rekonstrüksiyonu; allogreftin hazırlanışı (a), ameliyat esnasında patellar tendon defekti (b) ve defektli alanın allogreft ile onarımı sonrası (c), ameliyat sonrası yan grafi (d).
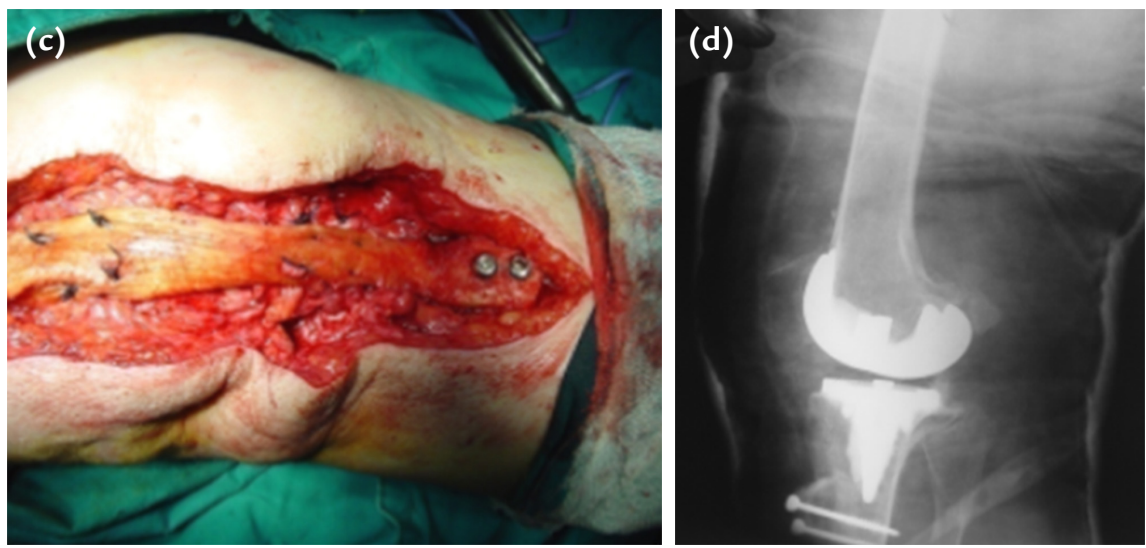
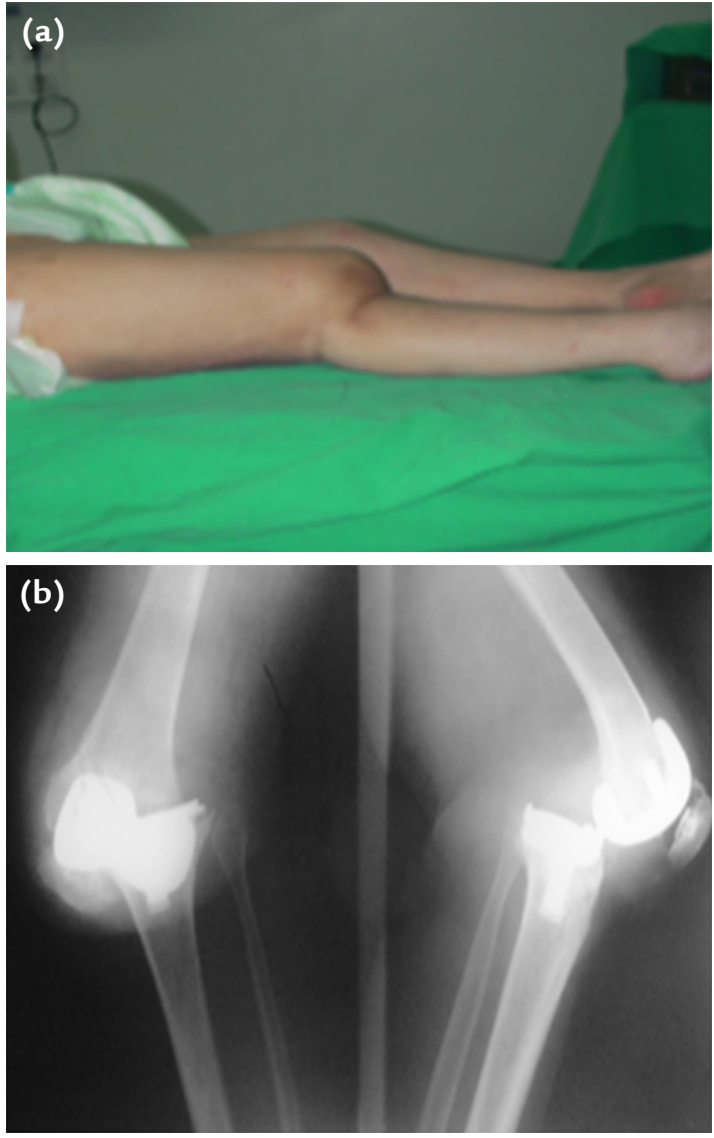

Şekil 6. a, b. TDP sonrası tibiofemoral çıkık; klinik görünüm (a) ile ön-arka ve yan grafiler (b). ekstansör mekanizma bozuklukları, ileri valgus dizlerde geniş posteriolateral gevşetme, polietilen insert kırılması veya enfeksiyon durumları gibi bazı etiyolojik nedenler de bildirilmiştir. ${ }^{[25]}$ Tedavide; komorbidite ve çıkığın mekanizması dikkate alınmalıdır. Duruma göre her hasta için en uygun tedavi yöntemi seçilerek avantajları ve riskleri dikkatlice analiz edilmelidir. ${ }^{[26]}$

\section{Kompleks Bölgesel Ağrı Sendromu}

Kompleks bölgesel ağrı sendromu (KBAS), TDP sonrası sebat eden ağrının nadir bir nedenidir. İnsidansı çalışmalara göre değişkenlik göstermektedir. Protez yerleştirilmiş ekstremitede KBAS'nin bazı klasik belirtilerinin tanıda güvenli olmamasının yanı sıra görüntülemenin de yorumlanmasını güçleştirmektedir. Ayrıca tanısında altın standart bir yöntem olmadığı için TDP sonrası KBAS'nin tanısı zor olabilmektedir. Abartılı ağrı ve tutukluğu olan hastalarda daha yaygın nedenler dışlandıktan sonra KBAS'den şüphe edilmelidir. Erken müdahale iyileşmede en önemli faktördür. Tedavisinde standart KBAS tedavileri yanında son yıllarda C vitamini tedavisi önem kazanmıştır. ${ }^{[28,29]}$

\section{Metallere Karşı Aşııı Duyarlılık}

Genel popülasyonda metallere karşı aşırı duyarlılık, yaklaşık \%15'lik bir insidansa sahiptir. Son yıllarda 

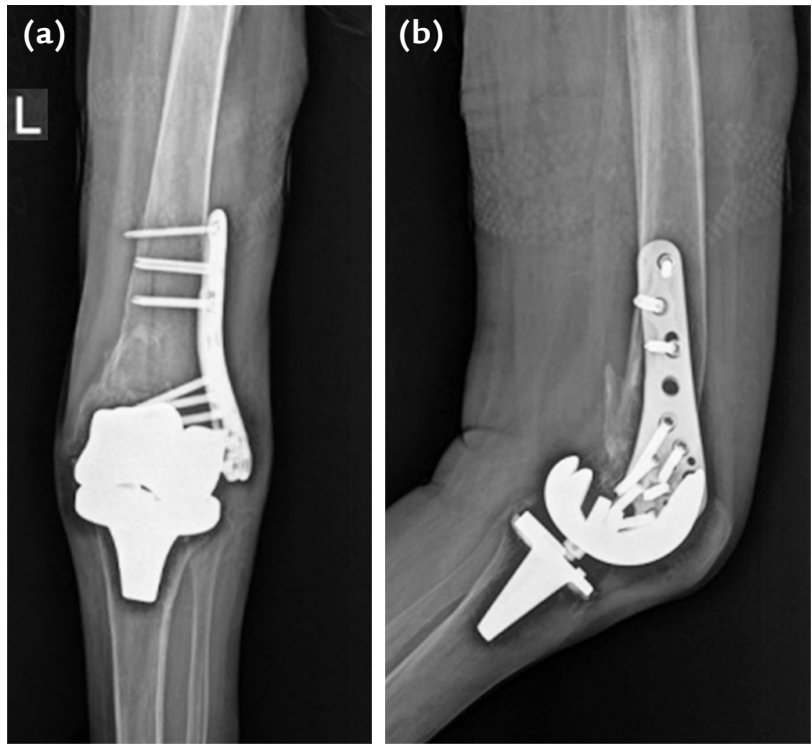

Şekil 7. a, b. Periprostetik distal femur kırığının kilitli plak ile tespiti; ön-arka (a) ve yan (b) grafi.

artan sayıda eklem replasmanına paralel TDP sonrası insidansı giderek artmaktadır. ${ }^{[30]}$ En sık nikel metaline karşı bildirilmiştir. Nikel normalde günlük yaşamın birçok nesnesinde ve maddesinde bulunmaktadır. Bu aşırı duyarlılık; kaşıntı, dermatit, döküntü, eritem, rinit gibi bulgularının yanında astım gibi daha ciddi semptomlar ile ortaya çıkabilmektedir. Metale karşı aşırı duyarlılık, TDP sonrası hastalarda ameliyat sonrası ağrı, şişlik, kemik rezorpsiyonu veya cilt nekrozu gibi belirtiler de görülebilmektedir. Hasta anamnezi ve şüpheli olgularda laboratuvar testlerinin yapılması bu tip belirtilerin önüne geçilmesi açısından önem arz etmektedir. Gereklilik halinde metale karşı aşırı duyarlılık açısından daha güvenli implantlar tercih edilmelidir. ${ }^{[30,31]}$

\section{Periprostetik Kırıklar}

Total diz protezi sonrası periprostetik kırıklar birçok ortopedi ve travmatoloji uzmanı için sorun teşkil etmektedir. Karmaşık kırık morfolojisi, osteopeni ile ilişkili yaralanmaların yüksek oranları ve yaralanma paternlerinin değişkenliği nedeniyle bu kırıkların tedavileri zordur. Total diz protezi ameliyatı sayısının artması ile beraber bu kırıkların da sıklığı giderek artmaktadır. Distal femoral periprostetik kırıklar primer TDP'de en yaygın görülen kırıklardır. İnsidansının \%0,2 ile \%1,8 arasında olduğu bildirilmektedir. Sıklıkla kilitli plaklama (Şekil 7) veya intramedüller çivileme ile tedavi edilmektedir. Tibial periprostetik kırıkları en az görülen kırık tipidir. Primer
TDP hastalarında insidansı \%0,07-\%0,1 civarındadır. Tedavilerinde çoğunlukla revizyon cerrahisi ile birlikte kemik grefti ve plaklama gerektirmektedir. Genel olarak bu kırıklar kaynamama, yanlış kaynama veya fonksiyonel bozukluk gibi komplikasyonlara daha açıktır. Tedavi yöntemi kişiye göre bireyselleştirilmelidir. Spesifik hasta veya yaralanma paternine göre optimal bir tedavi yöntemi seçilmelidir. ${ }^{[32]}$

\section{Periprostetik Eklem Enfeksiyonları}

Periprostetik eklem enfeksiyonu (PEE), TDP'nin en ciddi ve en çok korkulan komplikasyonudur. Katastrofik sonuçlara yol açabilmektedir. Hastaların yaşam kalitesini önemli derecede düşürmesinin yanında sağlık sisteminde de ciddi maliyet artışlarına neden olabilmektedir. ${ }^{[33]}$ Total diz protezi sonrası \%2 civarında görülmektedir. Yaş, cinsiyet, ırk, alkol tüketimi gibi demografik özelliklerin yanı sıra diyabet, obezite, romatoid artrit, diğer sistem enfeksiyonları, ASA düşüklüğü gibi komorbidite durumlar PEE'de önemli rol oynamaktadır. Ayrıca ameliyat süresi, kullanılan sement tipi (antibiyotikli-antibiyotiksiz) ve dren kullanımı gibi cerrahiye bağlı durumlar da etkili olmaktadır. ${ }^{[3,34]}$ Periprostetik eklem enfeksiyonundan kaçınmak için kilo verme, glisemik kontrol gibi önlemlerin yanı sıra antibiyotik profilaksisi, uygun cilt temizliği, turnikesiz ameliyat ve ameliyat süresinin kısaltılması gibi önlemler de alınmalıdır. Periprostetik eklem enfeksiyonlarında uygun tedavi yöntemi, genellikle implantın çıkartılması veya çıkartılmadan debridmanı şeklindedir. Bu da, uzun süreli hastanede kalmayı ve uzun süreli antibiyotik tedavisi uygulanmasını gerektirmektedir. ${ }^{[33]}$

\section{KAYNAKLAR}

1. Postler A, Lützner C, Beyer F, Tille E, Lützner J. Analysis of total knee arthroplasty revision causes. BMC Musculoskelet Disord 2018;19(1):1-6. Crossref

2. Putman S, Boureau F, Girard J, Migaud H, Pasquier G. Patellar complications after total knee arthroplasty. Orthop Traumatol Surg Res 2019;105(1):S43-51. Crossref

3. Healy WL, Della Valle CJ, lorio R, Berend KR, Cushner FD, Dalury DF, Lonner JH. Complications of total knee arthroplasty: standardized list and definitions of the Knee Society. Clin Orthop Relat Res 2013;471(1):215-20. Crossref

4. Sundaram K, Udo-Inyang I, Mont MA, Molloy R, HigueraRueda C, Piuzzi NS. Vascular Injuries in Total Knee Arthroplasty: A Systematic Review and Meta-Analysis. J Bone Joint Surg Rev 2020;8(1):e0051. Crossref

5. Padegimas EM, Levicoff EA, McGinley AD, Sharkey PF, Good RP. Vascular complications after total knee arthroplasty -a single institutional experience. J Arthroplasty 2016;31(7):1583-8. Crossref

6. Ravi B, Hosack L, Backstein D, Spangehl M. Recurrent hemarthrosis after total knee arthroplasty: evaluation and treatment. J Am Acad Orthop Surg 2019;27(17):652-8. Crossref 
7. Saksena J, Platts AD, Dowd GSE. Recurrent haemarthrosis following total knee replacement. Knee 2010;17(1):7-14. Crossref

8. Simons MJ, Amin NH, Scuderi GR. Acute wound complications after total knee arthroplasty: prevention and management. J Am Acad Orthop Surg 2017;25(8):547-55. Crossref

9. Harato K, Tanikawa H, Morishige $\mathrm{Y}$, Kaneda K, Niki Y. What are the important surgical factors affecting the wound healing after primary total knee arthroplasty? J Orthop Surg Res 2016;11(1):1-5. Crossref

10. Maheshwari AV, Tsailas PG, Ranawat AS, Ranawat CS. How to address the patella in revision total knee arthroplasty. Knee 2009;16(2):92-7. Crossref

11. Bonnin M, Lustig S, Huten D. Extensor tendon ruptures after total knee arthroplasty. Orthop Traumatol Surg Res 2016;102(1):S21-31. Crossref

12. Hamilton WG, Ammeen DJ, Parks NL, Goyal N, Engh GA, Engh Jr CA. Patellar cut and composite thickness: the influence on postoperative motion and complications in total knee arthroplasty. J Arthroplasty 2017;32(6):1803-7. Crossref

13. Pagnano MW, Trousdale RT. Asymmetric patella resurfacing in total knee arthroplasty. Am J Knee Surg 2000;13(4):22833. https://pubmed.ncbi.nlm.nih.gov/11269543/

14. Matz J, Howard JL, Morden DJ, MacDonald SJ, Teeter MG, Lanting BA. Do changes in patellofemoral joint offset lead to adverse outcomes in total knee arthroplasty with patellar resurfacing? A radiographic review. J Arthroplasty 2017;32(3):783-7.e1. Crossref

15. Kandhari VK, Desai MM, Bava SS, Wade RN. Digging Deeper into the Patello-Femoral Joint: Patello-Femoral Composite-A New Dimension for Overstuffing of Patello-Femoral Joint. J Clin Diagn Res 2017;11(3):RC04-7. Crossref

16. Chalidis BE, Tsiridis E, Tragas AA, Stavrou Z, Giannoudis PV. Management of periprosthetic patellar fractures: a systematic review of literature. Injury 2007;38(6):714-24. Crossref

17. Warschawski Y, Garceau S, Rutenberg TF, Dahduli O, Wolfstadt J, Backstein D. Revision total knee arthroplasty for patellar dislocation in patients with malrotated TKA components. Arch Orthop Trauma Surg 2020;140(6):77783. Crossref

18. Planckaert C, Larose $G$, Ranger $P$, Lacelle $M$, Fuentes $A$, Hagemeister $N$. Total knee arthroplasty with unexplained pain: new insights from kinematics. Arch Orthop Trauma Surg 2018;138(4):553-61. Crossref

19. Lamotte A, Neri T, Kawaye A, Boyer B, Farizon F, Philippot R. Medial patellofemoral ligament reconstruction for patellar instability following total knee arthroplasty: A review of 6 cases. Orthop Traumatol Surg Res 2016;102(5):607-10. Crossref

20. Conrad DN, Dennis DA. Patellofemoral crepitus after total knee arthroplasty: etiology and preventive measures. Clin Orthop Surg 2014;6(1):9. Crossref
21. Martin JR, Jennings JM, Watters TS, Levy DL, McNabb DC, Dennis DA. Femoral implant design modification decreases the incidence of patellar crepitus in total knee arthroplasty. J Arthroplasty 2017;32(4):1310-3. Crossref

22. Park CN, White PB, Meftah M, Ranawat AS, Ranawat CS. Diagnostic algorithm for residual pain after total knee arthroplasty. Orthopedics 2016;39(2):e246-52. Crossref

23. Vajapey SP, Blackwell RE, Maki AJ, Miller TL. Treatment of extensor tendon disruption after total knee arthroplasty: a systematic review. J Arthroplasty 2019;34(6):1279-86. Crossref

24. Garner MR, Gausden E, Berkes MB, Nguyen JT, Lorich DG. Extensor mechanism injuries of the knee: demographic characteristics and comorbidities from a review of 726 patient records. J Bone Joint Surg Am 2015;97(19):1592-6. Crossref

25. Jethanandani RG, Maloney WJ, Huddleston III JI, Goodman SB, Amanatullah DF. Tibiofemoral dislocation after total knee arthroplasty. J Arthroplasty 2016;31(10):2282-5. Crossref

26. Rouquette L, Erivan R, Pereira B, Boisgard S, Descamps $S$, Villatte G. Tibiofemoral dislocation after primary total knee arthroplasty: a systematic review. Int Orthop 2019;43(7):1599-609. Crossref

27. Lachman JR, Rehman S, Pipitone PS. Traumatic knee dislocations: evaluation, management, and surgical treatment. Orthop Clin North Am 2015;46(4):479-93. Crossref

28. Duenes M, Schoof L, Schwarzkopf R, Meftah M. Complex Regional Pain Syndrome Following Total Knee Arthroplasty. Orthopedics 2020;43(6):e486-91. Crossref

29. Jacques $H$, Jérôme $V$, Antoine $C$, Lucile $S$, Valérie $D$, Amandine L, Theofylaktos K, Olivier B. Prospective randomized study of the vitamin $C$ effect on pain and complex pain regional syndrome after total knee arthroplasty. Int Orthop 2021;45(5):1155-62. Crossref

30. Innocenti M, Vieri B, Melani T, Paoli T, Carulli C. Metal hypersensitivity after knee arthroplasty: fact or fiction? Acta Biomed 2017;88(Suppl 2):78-83. Crossref

31. Schmidt KJ, Huang PS, Colwell Jr CW, McCauleyJC, Pulido PA, Bugbee WD. Self-reported metal allergy and early outcomes after total knee arthroplasty. Orthopedics 2019;42(6):3304. Crossref

32. Lombardo DJ, Siljander MP, Sobh A, Moore DD, Karadsheh MS. Periprosthetic fractures about total knee arthroplasty. Musculoskelet Surg 2020;104(2):135-43. Crossref

33. Blanco JF, Díaz A, Melchor FR, da Casa C, Pescador D. Risk factors for periprosthetic joint infection after total knee arthroplasty. Arch Orthop Trauma Surg 2020;140(2):23945. Crossref

34. Kong L, Cao J, Zhang Y, Ding W, Shen Y. Risk factors for periprosthetic joint infection following primary total hip or knee arthroplasty: a meta-analysis. Int Wound J 2017;14(3):529-36. Crossref 